\title{
Óleos essenciais no tratamento de sementes de Phaseolus vulgaris L. durante o armazenamento
}

\section{Essential oils in the treatment of Phaseolus vulgaris L. seeds during storage}

\author{
Keidima Leite $^{1}$; Lisandro Tomas da Silva Bonome ${ }^{2 *}$; Gabriela Silva Moura ${ }^{3}$; Gilmar Franzener ${ }^{4}$
}

\begin{abstract}
Resumo: Os óleos essenciais apresentam metabólitos secundários com propriedades antibacteriana e antifúngica. Nesse sentido, objetivou-se com esse trabalho avaliar a incidência de fitopatógenos e a qualidade fisiológica de sementes de Phaseolus vulgaris L. cv. BRS Esplendor, tratadas com diferentes óleos essenciais em diferentes embalagens e tempos de armazenamento. Foram avaliados os óleos essenciais de canela (Cinnamomum zeylanicum), capim-limão (Cymbopogon citratus), cravo da índia (Syzgium aromaticum), erva-cidreira (Melissa officinalis), gengibre (Zingiber officinale), laranja-doce (Citrus sinensis), hortelã-pimenta (Mentha piperita.) e limão-taiti (Citrus aurantifolia), fungicida comercial e a testemunha, embalados em kraft ou pet. Aos 0, 60, 120 e 180 dias após o armazenamento das sementes, avaliou-se o teor de água; primeira contagem da germinação; porcentagem de germinação; índice de velocidade de emergência (IVE), emergência de plântulas, matéria seca e blotter test. Aos 120 e 180 dias após o armazenamento os tratamentos com óleos essenciais de $C$. aurantifolia e C. zeylanicum não afetaram a porcentagem de germinação das sementes quando acondicionadas em embalagem kraft. Entre as embalagens houve diferença significativa quando as sementes foram tratadas com os óleos essenciais de C. zeylanicum; C.sinensis e $M$. officinalis que reduziram a incidência do fungo do gênero Aspergillus spp. Os óleos essenciais de $C$. zeylanicum e $S$. aromaticum diminuíram a incidência de Penicillium spp., ambos armazenados em pet, tendo o óleo essencial de $C$. zeylanicum o comportamento semelhante ao fungicida comercial. A embalagem kraft foi mais eficiente em preservar a qualidade fisiológica das sementes tratadas de Phaseolus vulgaris L. do que a embalagem pet. No tempo zero de armazenamento, os tratamentos com $C$. sinensis e $S$. aromaticum promoveram efeito negativo sobre a qualidade fisiológica das sementes comparado a testemunha. O óleo essencial de $C$. citratus influenciou negativamente na porcentagem de germinação das sementes em relação aos demais óleos essenciais quando armazenado em saco kraft.
\end{abstract}

Palavras-chave: Feijoeiro; Metabólitos secundários; Fitotóxico; Sanidade; Vigor.

\begin{abstract}
Essential oils have secondary metabolites with antibacterial and antifungal properties. In this sense, the objective of this work was to evaluate the phytopathogen incidence and the physiological quality in seeds of Phaseolus vulgaris L. cv. BRS Splendor, treated with different essential oils in different packages and storage times. The essential oils of cinnamon (Cinnamomum zeylanicum), lemongrass (Cymbopogon citratus), clove (Syzgium aromaticum), lemon balm (Melissa officinalis), ginger (Zingiber officinale), sweet orange (Citrus sinensis), peppermint (Mentha piperita) and lemon-taiti (Citrus aurantifolia), commercial fungicide and the control, packed in kraft or pet. At 0, 60,120 and 180 days after storage of the seeds, the water content were evaluated; first count of germination; percentage of germination; emergence of seedlings; speed germination index, dry matter and blotter test. The treatments with essential oils of $C$. aurantifolia and $C$. zeylanicum did not affect the percentage of germination of the seeds during the storage when packed in kraft packaging. At 120 and 180 days after storage, treatments with essential oils of $C$. aurantifolia and $C$. zeylanicum did not affect the percentage of germination of the seeds when packed in kraft packaging. There was a significant effect among the packages within the same storage period for the essential oils of $C$. zeylanicum; C.sinensis and $M$. officinalis that decreased the incidence of the fungus of the genus Aspergillus spp. The essential oils of $C$. zeylanicum and $S$. aromaticum decreased the incidence of Penicillium spp., both stored in pet, the essential oil of $C$. zeylanicum being similar to the commercial fungicide. The kraft packaging was more efficient in preserving the physiological quality of the treated seeds of Phaseolus vulgaris L. than the pet package. At zero storage time, treatments with $C$. sinensis and $S$. aromaticum promoted a negative effect on the physiological quality of the seeds compared to the control. The essential oil of $C$. citratus influenced negatively the percentage of germination of the seeds in relation to the other essential oils when stored in a kraft packaging.
\end{abstract}

Key words: Common bean; Secondary metabolites; Phytotoxic; Sanity; Vigor.

\footnotetext{
*Autor para correspondência

Recebido para publicação em 25/02/2018; aprovado em 11/03/2018

${ }^{1}$ Engenheira Agrônoma, Universidade Federal da Fronteira Sul - UFFS, E-mail: keidima.agronomia@gmail.com

${ }^{2}$ Professor do Curso de Agronomia da Universidade Federal da Fronteira Sul - UFFS; BR 158, Km 405, s/n - Zona Rural; CEP: 85301-970, Laranjeiras do Sul, Paraná, Brasil, E-mail: lisandro.bonome@uffs.edu.br

${ }^{3}$ Pós-doutoranda em Agroecologia e Desenvolvimento Rural Sustentável (PNPD-CAPES), Universidade Federal da Fronteira Sul - UFFS, Campus Laranjeiras do Sul - PR; E-mail: bismoura@ hotmail.com

${ }^{4}$ Professor do Curso de Agronomia da Universidade Federal da Fronteira Sul - UFFS; BR 158, Km 405, s/n - Zona Rural; CEP: 85301-970, Laranjeiras do Sul, Paraná, Brasil, E-mail: gilmar.franzener@uffs.edu.br
} 


\section{INTRODUÇÃO}

O feijoeiro comum (Phaseolus vulgaris L.) é uma das leguminosas mais cultivadas do mundo. A espécie é uma das principais fontes de proteínas de países em desenvolvimento, contribuindo, em média, com $36 \%$ do total de proteínas requeridas diariamente por uma pessoa (SCHMUTZ et al., 2014). Além de ser rico como fonte proteica, apresenta elevado conteúdo de carboidratos, vitaminas e minerais (COSTA et al., 2006; RABELO et al., 2006).

O Brasil se destaca como o terceiro maior produtor mundial da cultura, sendo o estado do Paraná o maior produtor nacional, com $75 \%$ da produção provenientes da agricultura familiar (CONAB, 2017). Entre as variedades mais conhecidas e consumidas estão o feijão preto, o carioca e o roxinho (RABELO et al., 2006).

Apesar de sua importância econômica, a cultura do feijoeiro pode ser acometida por diversas pragas e doenças que podem ocasionar danos e perdas significativas, como a diminuição do valor nutricional dos grãos e da qualidade fisiológica das sementes, o que, consequentemente, determina a redução do valor de mercado ou até mesmo a condenação de lotes de sementes e/ou grãos (CANEPPELE et al., 2003).

Em geral, os agricultores familiares têm preferência em semear sementes crioulas adquiridas por meio de trocas com vizinhos, familiares, feiras ou de sua própria produção. Tais sementes, em sua maioria, são armazenadas de uma safra para outra e possuem baixo ou nenhum controle de sanidade, apresentando elevado potencial para a infestação de patógenos associados a elas (IAPAR, 2007). As sementes podem ser fontes de disseminação e de sobrevivência de fitopatógenos (SILVA et al., 2014), mantendo sua viabilidade durante o armazenamento e matando as sementes e/ou contaminando o solo e a planta após sua semeadura e emergência (BRAGANTINI, 2005).

$\mathrm{O}$ principal método de controle de patógenos em sementes é por meio de tratamento com fungicidas, os quais podem conter os mais variados princípios ativos. Embora eficientes, os métodos químicos de controle de fungos podem causar efeitos tóxicos ao ser humano e ao ambiente. Além disso, o uso intensivo desses produtos químicos pode promover a seleção de patógenos resistentes (GHINI; KIMATI, 2000).

Diante disso, produtos naturais, como extratos e óleos essenciais, por exemplo, vêm sendo avaliados como alternativa no tratamento de sementes. Esses derivados vegetais possuem metabólitos secundários que pertencem a diferentes classes de substâncias químicas, apresentando atividades biológicas que podem ser elicitoras ou antimicrobianas, podendo ser uma alternativa no controle de fitopatogênicos (CUNHA, 2015; OOTANI et al., 2013; SILVA, 2014). Neste contexto, óleos essenciais podem representar potencial alternativa no tratamento de sementes, visando ao controle de fitopatógenos, embora seu efeito protetor, bem como sobre a qualidade fisiológica, ainda seja pouco conhecido.

Algumas pesquisas têm demonstrado resultados positivos em relação ao uso de óleos essenciais na manutenção da qualidade fisiológica das sementes e no controle de fungos de armazenamento. Mata et al. (2009) observaram que o óleo essencial de Pimpinella anisum (Anis), nas concentrações de 1,0; 1,5; 2,0 e 2,5\%, inibiram a ocorrência de Cladosporium spp., Curvularia spp. e
Nigropora spp em sementes de mandacaru quando comparado a testemunha.

Gomes et al. (2016) observaram que os óleos essenciais de Copaifera langsdorffii (Copaíba) e Ocimum basilicum (Manjericão) reduziram em 6 e $4 \%$ a incidência do Fusarium spp. em sementes de Phaseolus lunatus L., respectivamente. Mondego et al. (2014) testando a eficiência do óleo essencial de Copaifera sp., em sementes de Pseudobombax marginatum (Embiratanha), no controle de fitopatógenos, relataram que, na concentração de $1 \%$, o óleo foi eficaz na redução da incidência de Aspergillus spp., com diminuição de $14 \%$ quando comparado a testemunha. Nas concentrações de 1 e 1,5\%, o óleo essencial foi efetivo no controle de Chaetomium spp e Curvularia spp., os quais não diferiram do tratamento com fungicida.

Tendo em vista a necessidade de minimizar os danos causados por fungos às sementes de feijão armazenadas e devido ao interesse por produtos alternativos com ação fungicida, menos danosos à saúde humana e ao meio ambiente, o objetivo foi avaliar o efeito da aplicação de óleos essenciais na qualidade fisiológica e sanidade de sementes de Phaseolus vulgaris L. durante o armazenamento.

\section{MATERIAL E MÉTODOS}

O experimento foi realizado nos Laboratórios de Fisiologia Vegetal, Germinação e Crescimento de Plantas e em casa de vegetação da Universidade Federal da Fronteira Sul (UFFS), Laranjeiras do Sul - PR.

As sementes de feijoeiro da variedade BRS Esplendor foram obtidas na Cooperativa Coprossel em Laranjeiras do Sul - PR. Constituíram tratamentos os óleos essenciais de canela (Cinnamomum zeylanicum Blume.), capim-limão (Cymbopogon citratus (DC) Stapf.), cravo da índia (Syzgium aromaticum L. Merr. \& L.M. Perry), erva-cidreira (Melissa officinalis L.), gengibre (Zingiber officinale [Willd.] Roscoe.), laranja-doce (Citrus sinensis (L.) Osbeck.), hortelãpimenta (Mentha piperita L.) e limão-taiti (Citrus aurantifolia (Christm). Swingle.), adquiridos na forma comercial, na Casa das Essências Quinari localizada em Ponta Grossa - PR. O fungicida Derosal Plus ${ }^{\circledR}(2,5 \mathrm{~mL} / \mathrm{kg}) \mathrm{da}$ empresa Bayer foi obtido no comércio local.

Para cada tratamento foram colocados em sacos plásticos de polietileno $1,3 \mathrm{~kg}$ de sementes de feijão e tratadas com $3 \mathrm{~mL}$ de óleo essencial, agitando-se até que as sementes apresentassem uma película homogênea de óleo aderida sobre o tegumento. Para o tratamento com fungicida foram adicionados 3,3 $\mathrm{mL}$ do produto de acordo com a recomendação do fabricante. $\mathrm{Na}$ testemunha foram adicionados $3 \mathrm{~mL}$ de água destilada estéril. Após o tratamento, as sementes foram acondicionadas em dois tipos de embalagem, sacos kraft e garrafas pet, e armazenadas no escuro sob a temperatura de $25^{\circ} \mathrm{C}$.

Ao zero, 60, 120 e 180 meses após o armazenamento, uma amostra de sementes de cada tratamento foi retirada das embalagens e procedidos os testes de germinação, primeira contagem de germinação, índice de velocidade de emergência, porcentagem de emergência, biomassa seca das plântulas, teor de água das sementes e Blotter Test.

Para o teste de germinação, quatro repetições de 50 sementes foram distribuídas sobre duas folhas de papel germitest, umedecidas com quantidade de água equivalente a 
2,5 vezes a massa do papel não hidratado, coberto com uma terceira folha previamente hidrata e, logo após, confeccionados em forma de rolos e mantidos em germinador do tipo Mangelsdorf à temperatura de $25^{\circ} \mathrm{C}$ e luz constante. No quinto dia após a montagem do teste, foram computadas o número as plântulas normais como sendo a primeira contagem de germinação e, no nono, foram classificadas em normais, anormais, mortas e dormentes (BRASIL, 2009b). Computaram-se as plântulas normais no quinto dia após a instalação do teste e os resultados foram expressos em porcentagem.

Para o índice de velocidade de emergência e porcentagem de emergência de plântulas realizou-se a semeadura de 50 sementes por repetição de cada tratamento em bandejas de isopor próprias para a produção de mudas que possuíam 128 células. Em cada bandeja foram alocados dois tratamentos nas extremidades externas, sendo semeada uma semente por célula, com aproximadamente $3 \mathrm{~cm}$ de profundidade. Como substrato foi utilizada a proporção de 2:1 de terra e areia, peneiradas em malha de $2 \mathrm{~mm}$ para maior homogeneidade da mistura.

As avaliações foram realizadas desde a emergência da primeira plântula emergida aos 3 dias após a semeadura até a estabilização da emergência que ocorreu no $11^{\circ}$ dia. Foram consideradas plantas emergidas as que apresentavam $3 \mathrm{~cm}$ de altura. O índice de velocidade de emergência foi calculado de acordo com fórmula proposta por Maguire (1962).

$\mathrm{IVG}=\mathrm{N} 1 / \mathrm{D} 1+\mathrm{N} 2 / \mathrm{D} 2+\ldots+\mathrm{Nn} / \mathrm{Dn}$

Em que: $\mathrm{IVG}=$ índice de velocidade de emergência; $\mathrm{N}=$ número de plântulas verificadas no dia da contagem; $\mathrm{D}=$ número de dias após a semeadura em que foi realizada a contagem.

A biomassa seca das plântulas foi realizada após a avaliação do índice de velocidade de emergência. No $11^{\circ}$ dia, a parte aérea das plântulas foi cortada com o auxílio de tesoura e, em seguida, foram colocadas 10 plântulas em cada saco kraft e levados para secar em uma estufa com circulação forçada de ar a $65^{\circ} \mathrm{C}$, por $72 \mathrm{~h}$. A biomassa seca das plântulas foi obtida por meio de pesagem em uma balança analítica com precisão de 0,001 g (NAKAGAWA, 1999).

$\mathrm{O}$ grau de umidade das sementes foi conduzido em estufa a $105^{\circ} \mathrm{C}$, durante $24 \mathrm{~h}$, utilizando-se duas subamostras por tratamento (BRASIL, 2009), e os resultados foram expressos em porcentagem.

A qualidade sanitária das sementes foi avaliada de acordo com o Manual para Análises Sanitária de Sementes (BRASIL, 2009a). Foram utilizadas 200 sementes por tratamento. As amostras foram distribuídas em 8 repetições de 25 sementes, em caixa do tipo gerbox, contendo uma folha de papel mata borrão esterilizada em autoclave e umedecida com água destilada. As caixas foram colocadas para incubação em câmara de germinação tipo BOD, à temperatura de $25^{\circ} \mathrm{C}$ por $24 \mathrm{~h}$, após, foram transferidas para refrigerador a temperatura de $5{ }^{\circ} \mathrm{C}$, onde permaneceram por $24 \mathrm{~h}$, e, em seguida, recolocadas na $\mathrm{BOD}$ à temperatura de $25^{\circ} \mathrm{C}$ por 5 dias. Concluídos os 7 dias foi realizada a avaliação da incidência de fitopatógenos com o auxílio de microscópio estereoscópico e ótico.
O delineamento experimental utilizado foi o inteiramente casualizado, em esquema fatorial $(10 \times 2 \times 4)$ com 4 repetições, sendo 10 tratamentos, 2 tipos de embalagens e 4 períodos de armazenamento. Os dados foram avaliados pelo teste Tukey a 5\% de probabilidade de erro. Os dados de sanidade foram transformados por meio da fórmula de raiz quadrada $(\wedge 5)$ com o auxílio do programa Sisvar 5.6 (FERREIRA, 2014).

\section{RESULTADOS E DISCUSSÃO}

O Teste Padrão de Germinação em Laboratório apresentou $90 \%$ de sementes de feijoeiro germinadas e $11 \%$ de umidade. Os valores obtidos de germinação e umidade inicial para o armazenamento na presente pesquisa enquadram-se ao estabelecido pela Instrução normativa $n^{\circ} 45$, de 17 de setembro de 2013.(MAPA, 2013).

Com relação ao teor de água, observou-se menor variação nas sementes armazenadas em embalagem pet do que nas de kraft (Figuras 1 A e 1B). Enquanto nas embalagens pet a umidade oscilou entre 10 e $11 \%$, durante o armazenamento nas embalagens kraft a oscilação foi de 8,5 a $11 \%$. As embalagens kraft são permeáveis, portanto, permitem trocas de umidade com o ambiente externo, enquanto que as embalagens pet são impermeáveis não permitindo esse intercâmbio de vapor de água (BONOME et al., 2009). A umidade entre 9 e $11 \%$ é considerada ótima para a conservação de sementes de feijão, visto que, nessa condição, a semente apresenta atividade metabólica muito reduzida, podendo ser preservada por longos períodos. Além disso, a baixa umidade das sementes é um fator limitante para a proliferação de microrganismos.

Quanto a porcentagem de germinação ao nono dia houve comportamento distinto tanto entre os tratamentos quanto para a embalagem, entre e dentro desses fatores. Não houve interação significativa entre o tempo de armazenamento e tipo de embalagem. No tempo zero de armazenamento, os tratamentos com $C$. sinensis e $S$. aromaticum promoveram efeito negativo sobre a qualidade fisiológica das sementes, com redução da germinação em 48 e 60 pontos percentuais em relação à testemunha, respectivamente (Tabela 1). Os demais tratamentos, sem armazenamento, não promoveram redução significativa da germinação em relação à testemunha.

No tempo zero, a redução no número de sementes germinadas quando tratadas com $S$. aromaticum indica possível efeito fitotóxico na quantidade do óleo utilizada (OLIVEIRA et al., 2011). Além disso, a quantidade de óleo aplicado direto sobre a superfície das sementes no início do período de armazenamento pode ter afetado a germinação das mesmas, não sendo evidenciado tal comportamento no decorrer dos demais períodos de armazenamento.

A presença de compostos como o eugenol, um dos principais constituintes do óleo essencial de S. aromaticum, quando em alta concentração, pode ocasionar toxicidade nas sementes (OLIVEIRA et al., 2011). No óleo essencial de $S$. aromaticum, encontra-se em torno de 70 a $85 \%$ do componente eugenol (BROWN \& MORRA 1995; BROWN et al. 1991; FERRÃO, 1993; ORTIZ, 1992) e no óleo extraído das folhas desta árvore esse componente pode representar cerca de 95\% (RAINA et al., 2001). 
Figura 1. Umidade de sementes de P. vulgaris em diferentes tratamentos, tempos de armazenamento (meses) e embalagens, (A) kraft e (B) pet.
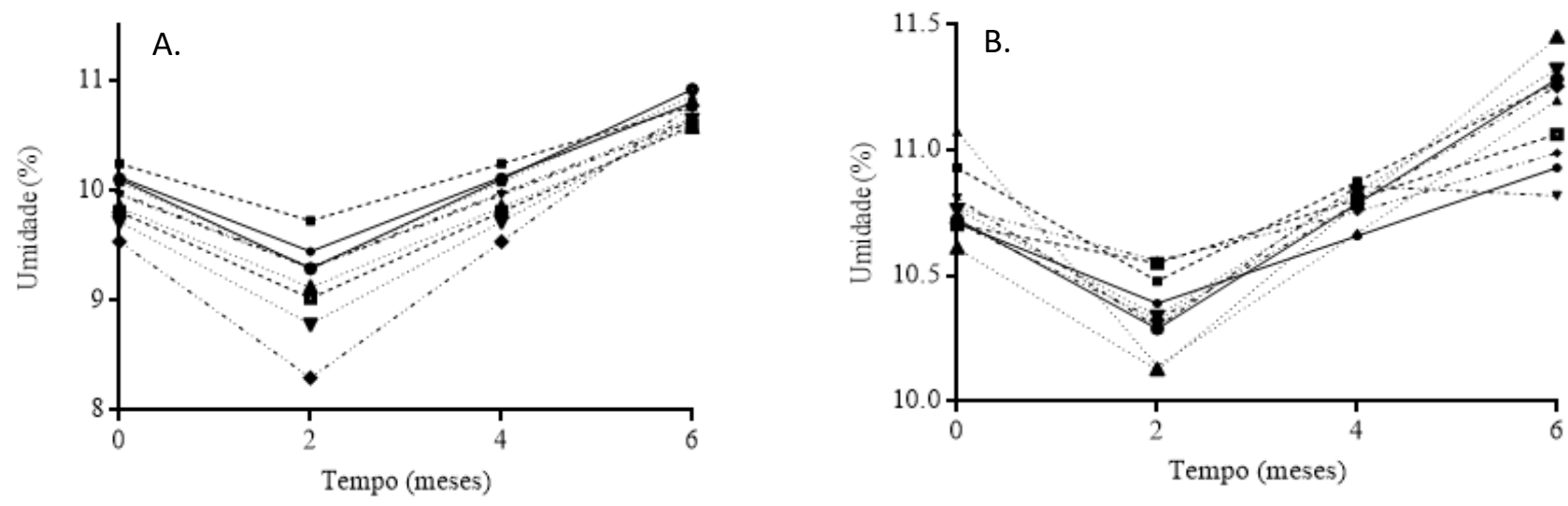

$$
\begin{array}{llll}
\rightarrow & \text { Testemunha } & \rightarrow & \text { M. piperita } \\
\cdots & \text { C. sinensis } & - & \text { M. officinalis } \\
\cdots & \text { E. caryophyllata } & \bullet & \text { Z. officinale } \\
\cdots & \text { C. citratus } & \boldsymbol{\nabla} & \text { C. zeylanicum } \\
\cdots & \text { C. aurantifolia } & - & \text { fungicida }
\end{array}
$$

Tabela 1. Porcentagem de germinação ao nono dia em sementes de P. vulgaris, tratadas com diferentes óleos essenciais, tipo de embalagem e tempos de armazenamento (dias).

\begin{tabular}{|c|c|c|c|c|c|c|c|}
\hline \multicolumn{8}{|c|}{ Tempos de Armazenamento e Tipos de Embalagem } \\
\hline \multirow{2}{*}{ Tratamentos } & \multirow[t]{2}{*}{0} & \multicolumn{2}{|c|}{60} & \multicolumn{2}{|c|}{120} & \multicolumn{2}{|c|}{180} \\
\hline & & Pet & Kraft & Pet & Kraft & Pet & Kraft \\
\hline C. zeylanicum & $84 \mathrm{Aa}$ & $38 \mathrm{ABCDa}$ & $14 \mathrm{Ba}$ & $51 \mathrm{Aa}$ & $71 \mathrm{ABa}$ & $48 \mathrm{Aa}$ & $75 \mathrm{Aa}$ \\
\hline C. aurantifolia & 79 Aba & $33 \mathrm{BCDb}$ & $65 \mathrm{Aa}$ & $42 \mathrm{Ab}$ & $71 \mathrm{ABa}$ & $45 \mathrm{Ab}$ & $77 \mathrm{Aa}$ \\
\hline C. sinensis & $34 \mathrm{BCa}$ & $65 \mathrm{Aba}$ & $87 \mathrm{Aa}$ & $62 \mathrm{Aa}$ & $31 \mathrm{Bb}$ & 67 Aa & $40 \mathrm{ABa}$ \\
\hline C. citratus & $41 \mathrm{ABCa}$ & $0 \mathrm{Db}$ & $55 \mathrm{ABa}$ & $31 \mathrm{Aa}$ & $33 \mathrm{Ba}$ & $38 \mathrm{Aa}$ & $26 \mathrm{Ba}$ \\
\hline M. officinalis & $47 \mathrm{ABCa}$ & $45 \mathrm{ABCDa}$ & $44 \mathrm{ABa}$ & $32 \mathrm{Aa}$ & $46 \mathrm{ABa}$ & $41 \mathrm{Aa}$ & $50 \mathrm{ABa}$ \\
\hline M. piperita & $80 \mathrm{Aa}$ & $46 \mathrm{ABCa}$ & $71 \mathrm{Aa}$ & $43 \mathrm{Aa}$ & $41 \mathrm{ABa}$ & $51 \mathrm{Aa}$ & $47 \mathrm{ABa}$ \\
\hline S. aromaticum & $22 \mathrm{Ca}$ & $13 \mathrm{CDb}$ & $87 \mathrm{Aa}$ & $42 \mathrm{Aa}$ & $62 \mathrm{ABa}$ & $35 \mathrm{Aa}$ & $45 \mathrm{ABa}$ \\
\hline Z. officinale & $54 \mathrm{ABCa}$ & $75 \mathrm{Aba}$ & $89 \mathrm{Aa}$ & 48 Аа & $44 \mathrm{ABa}$ & $43 \mathrm{Ab}$ & $72 \mathrm{Aa}$ \\
\hline Fungicida & 77 Aba & $67 \mathrm{Aba}$ & $83 \mathrm{Aa}$ & $61 \mathrm{Aa}$ & $71 \mathrm{ABa}$ & $64 \mathrm{Aa}$ & $65 \mathrm{Aa}$ \\
\hline Testemunha & $82 \mathrm{Aa}$ & $79 \mathrm{Aa}$ & $80 \mathrm{Aa}$ & $71 \mathrm{Aa}$ & $82 \mathrm{Aa}$ & $72 \mathrm{Aa}$ & $73 \mathrm{Aa}$ \\
\hline $\mathrm{CV} \%$ & \multicolumn{7}{|c|}{36,33} \\
\hline
\end{tabular}

Médias seguidas de mesma letra maiúscula na coluna e minúscula na linha (dentro do mesmo tempo em embalagens diferentes) não diferem entre si pelo teste de Tukey a $5 \%$ de probabilidade.

Resultados semelhantes foram obtidos por Gomes e colaboradores (2016) que observaram que o óleo de $S$. aromaticum, na concentração de $2 \mathrm{~mL} / \mathrm{L}$, interferiu negativamente no vigor das sementes de P. lunatus L. Lorenzi e Matos (2002) ressaltam que determinados constituintes, como timol, metil-chavicol, linalol, eugenol, cineol e pireno, em óleos essenciais de espécies vegetais, quando em altas concentrações, podem reduzir o número de sementes germinadas.

Pierre (2009), avaliando diferentes concentrações do óleo essencial de $S$. aromaticum sobre a germinação de sementes de Coffea sp.(Café), observou que o óleo essencial nas concentrações de $0,5 \%$ e $1,0 \%$ e o extrato a $20 \%$, promoveram aumento da germinação de sementes de Coffea sp. em relação à testemunha. $\mathrm{O}$ autor ainda ressalta que o óleo não interferiu na germinação das sementes diferindo do tratamento com fungicida clorotalonil.

Pesquisa realizada por Teixeira (2010) também evidenciou que o óleo essencial de $C$. zeylanicum, na concentração de $0,1 \%$, assegurou a germinação de sementes de Zea mays (Milho) em $84 \%$. Quando as sementes de Zea mays foram tratadas com óleo essencial de S. aromaticum a $0,1 \%$, significativa porcentagem de germinação (89\%) foi verificada. Nas condições deste trabalho, isso não foi evidenciado provavelmente devido ao fato de o óleo ter sido usado na forma concentrada.

Corrobora com o presente trabalho a pesquisa realizada por Rossi et al. (2012) que avaliaram óleos essenciais de diferentes espécies vegetais da região do Mediterrâneo, entre elas, o óleo essencial de Citrus bergamia (Laranjabergamota), que influenciou negativamente, com aumento da concentração de 1 para $50 \%$, na germinação de sementes de Triticum aestivum (Trigo) e Zea mays. Stülp et al. (2011) também constataram que o óleo essencial de $C$. sinensis (produto comercial Oroborß) na concentração de 20\% diminuiu significativamente a germinação das sementes de trigo. De acordo com Lemes et al. (2016), o óleo essencial de Citrus spp. pode ocasionar fitotoxicidade, em função da presença de compostos tóxicos ou oxidação enzimática do óleo sobre a semente, interferindo negativamente na germinação. 
Aos sessenta dias após o armazenamento, foi verificado que as sementes acondicionadas em embalagens kraft tiveram menores perdas do poder germinativo do que aquelas armazenadas em embalagem pet para os tratamentos com $C$. aurantifolia, $S$. aromaticum e $C$. citratus em que as perdas foram de 32,74 e 55 pontos percentuais quando acondicionadas em garrafa pet, respectivamente. $\mathrm{Na}$ embalagem kraft aos sessenta dias de armazenamento não houve diferença estatística entre os tratamentos, com exceção para o tratamento de $C$. zeylanicum que apresentou germinação inferior aos demais. Aos cento e vinte dias de armazenamento, os tratamentos em pet não diferiram estatisticamente entre si, mas quando armazenados em sacos kraft, os tratamentos com $C$. sinensis e $C$. citratus diminuíram a germinação em 51 e 49 pontos percentuais em relação à testemunha. Aos cento e oitenta dias de armazenamento, apenas o tratamento de $C$. aurantifolia se diferiu em relação à embalagem, apresentando menor porcentagem de germinação quando armazenado em pet, indicando que a garrafa pet foi prejudicial à semente para esse caso. No geral, o óleo essencial de $C$. citratus promoveu menor porcentagem de germinação em relação aos demais óleos essenciais quando armazenado em saco kraft.

Pesquisa realizada por Gonçalves et al. (2009) mostrou que sementes de feijoeiro tratadas com extrato de $S$. aromaticum a 10\%, e mantidas em embalagens metálicas, diminuíram o índice de velocidade de germinação. Azevedo et al. (2003) ressaltam a importância de práticas adequadas de armazenamento para garantir a qualidade fisiológica das sementes. Almeida et al. (1999), estudando a melhor forma de armazenamento de sementes de gergelim, verificaram que a embalagem impermeável permitiu melhor conservação das sementes, enquanto que a embalagem permeável (saco de pano) favoreceu a aceleração do processo de deterioração ao longo do armazenamento.

No geral, a embalagem recomendada para a conservação de sementes em pequenas propriedades rurais é a impermeável, devido à inexistência de sistema de controle de temperatura e umidade relativa nos locais de armazenamento. Em embalagens permeáveis, como papel, juta, algodão e plástico trançado, a quantidade de água da semente modificase conforme as variações da umidade do ar, prejudicando a qualidade das sementes. Para embalagens semipermeáveis, como sacos plásticos finos ou de polietileno, e sacos de papel multifoliado laminados com polietileno, existem resistência às trocas, no entanto, não impede completamente a passagem da umidade. Por outro lado, embalagens impermeáveis como sacos plásticos com espessura maior que $0,125 \mathrm{~mm}$, não há influência da umidade do ar externo sobre as sementes (POPINIGIS, 1985).

Embora a embalagem impermeável seja a mais recomendada para a conservação de sementes em condição onde não há controle de temperatura e umidade relativa do ar, quando houve o tratamento com os óleos essenciais a embalagem em questão diminuiu a porcentagem de germinação, sendo notoriamente a embalagem que menos preservou a qualidade fisiológica das sementes. Por outro lado, sendo os óleos essenciais constituídos por compostos voláteis (BIASI; DESCHAMPS, 2009), assim é possível que os vapores liberados por esses produtos e aprisionados na embalagem impermeável tenham causado fitotoxidez às sementes, reduzindo e/ou retardando a germinação das mesmas. É possível também que a embalagem kraft tenha apresentado efeito absorvente, reduzindo a concentração de óleo essencial na semente. Assim, nas condições deste experimento, o armazenamento das sementes em embalagem tipo kraft apresenta-se o mais adequado em preservar a qualidade fisiológica das sementes.

Para o teste de vigor de emergência de plântulas não foi observada diferença estatística entre os tratamentos, enquanto que, no teste de primeira contagem de plântulas, diferenças foram verificadas (Tabela 2). Os tratamentos com óleos essenciais de $S$. aromaticum, Z. officinale e $C$. citratus ocasionaram diminuição do vigor da semente, no tempo zero, apresentando 1,3 e 5\% de germinação no quinto dia de avaliação, respectivamente. Após sessenta dias de armazenamento houve diferença entre as embalagens, mostrando que, no geral, as sementes armazenadas em garrafa pet tiveram menor valor de germinação no quinto dia após a semeadura quando comparado com o kraft. Nas embalagens kraft pode-se notar diferenças entre os tratamentos, em que os óleos essenciais de Z. officinale, $C$. sinensis e a testemunha apresentaram maior média de germinação e os tratamentos com M. officinalis, M. piperita, C. citratus, C. aurantifolia, $S$. aromaticum e $C$. zeylanicum retardaram a germinação das sementes.

Tabela 2. Porcentagem de germinação aos cinco dias após semeadura em sementes de $P$. vulgaris, tratadas com diferentes óleos essenciais, tipo de embalagem e tempos de armazenamento (dias).

\begin{tabular}{|c|c|c|c|c|c|c|c|}
\hline \multicolumn{8}{|c|}{ Tempos de Armazenamento e Tipos de Embalagem } \\
\hline \multirow{2}{*}{ Tratamentos } & 0 & \multicolumn{2}{|c|}{60} & \multicolumn{2}{|c|}{120} & \multicolumn{2}{|c|}{180} \\
\hline & & Pet & Kraft & Pet & Kraft & Pet & Kraft \\
\hline C. zeylanicum & $25 \mathrm{ABCa}$ & $1 \mathrm{Aa}$ & $0 \mathrm{Ba}$ & $2 \mathrm{Aa}$ & $3 \mathrm{Ca}$ & 0Aa & $11 \mathrm{Aa}$ \\
\hline C. aurantifolia & $19 \mathrm{ABCa}$ & $2 \mathrm{Aa}$ & $8 \mathrm{Ba}$ & $0 \mathrm{Ab}$ & $24 \mathrm{ABCa}$ & $2 \mathrm{Aa}$ & $12 \mathrm{Aa}$ \\
\hline C. sinensis & $34 \mathrm{ABa}$ & $3 \mathrm{Ab}$ & 39Aa & $9 \mathrm{Ab}$ & $35 \mathrm{Aa}$ & $10 \mathrm{Aa}$ & 6Aa \\
\hline C. citratus & $5 \mathrm{Ca}$ & $0 \mathrm{Aa}$ & $9 \mathrm{Ba}$ & $0 \mathrm{Aa}$ & $11 \mathrm{ABCa}$ & $5 \mathrm{Aa}$ & $0 \mathrm{Aa}$ \\
\hline M. officinalis & $23 \mathrm{ABCa}$ & $3 \mathrm{Aa}$ & $10 \mathrm{Ba}$ & $0 \mathrm{Aa}$ & $6 \mathrm{BCa}$ & $6 \mathrm{Aa}$ & $12 \mathrm{Aa}$ \\
\hline M. piperita & $36 \mathrm{ABa}$ & $2 \mathrm{Aa}$ & $9 \mathrm{Ba}$ & $0 \mathrm{Aa}$ & $6 \mathrm{BCa}$ & $13 \mathrm{Aa}$ & $0 \mathrm{Aa}$ \\
\hline S. aromaticum & $1 \mathrm{Ca}$ & $0 \mathrm{Aa}$ & $2 \mathrm{Ba}$ & OAa & $15 \mathrm{ABCa}$ & 0Aa & OAa \\
\hline Z. officinale & $3 \mathrm{Ca}$ & $3 \mathrm{Ab}$ & 39Aa & $18 \mathrm{Aa}$ & $32 \mathrm{Aba}$ & OAa & $13 \mathrm{Aa}$ \\
\hline Fungicida & $9 \mathrm{ABa}$ & $1 \mathrm{Ab}$ & $21 \mathrm{ABa}$ & $5 \mathrm{Aa}$ & $19 \mathrm{ABCa}$ & $3 \mathrm{Aa}$ & $16 \mathrm{Aa}$ \\
\hline Testemunha & $41 \mathrm{Aa}$ & $27 \mathrm{Ab}$ & $40 \mathrm{Aa}$ & $19 \mathrm{Ab}$ & 37Aa & $11 \mathrm{Aa}$ & $12 \mathrm{Aa}$ \\
\hline
\end{tabular}
$\mathrm{CV} \%$ 36,33

Médias seguidas de mesma letra maiúscula na coluna, e minúscula na linha (dentro do mesmo tempo em embalagens diferentes) não diferem entre si pelo teste de Tukey a $5 \%$ de probabilidade. 
Dudai e colaboradores (1999) observaram que os óleos essenciais de várias espécies de plantas, dentre elas o $C$. citratus, mesmo em baixas concentrações, inibiram a germinação das sementes de Amaranthus blitoides (Ervaaranha), Amaranthus palmeri (Caruru), Euphorbia hirta (Erva de Santa Lluzia), Sinaps nigra (Sabugueiro), Trifolium campestris (Trevinho) e Solanum lycopersicum (Tomate). Redução de vigor nas sementes de Zea mays foi observada quando tratadas com óleos essenciais de Mentha sp., e Thymus vulgaris L. (Tomilho) (JARDINETTI et al., 2011), Corymbia citriodora (Eucalipto-limão) e Eucalyptus camaldulensis (Eucalipto-vermelho) (DOMENE et al., 2016).

Conforme salienta Maraschin-Silva (2004) a utilização de óleos essenciais em tratamentos de sementes pode afetar a germinação devido a presença de alguns compostos majoritários que podem prejudicar a absorção de água pela semente e, consequentemente impedir e/ou retardar os processos bioquímicos de germinação.

Aos cento e vinte dias de armazenamento, as sementes tratadas com C. aurantifolia, M. officinalis, S. aromaticum, $M$. piperita e $C$. citratus acondicionados em embalagem pet não apresentaram germinação na primeira contagem. Aos cento e oitenta dias de armazenamento, não houve diferenciação estatística pelo teste de médias entre as embalagens e nem entre os tratamentos. É possível observar, de maneira geral, que durante todo o armazenamento as embalagens de kraft foram mais eficientes em preservar o vigor das sementes do que a garrafa pet. Possivelmente isso deve-se ao fato de que a embalagem kraft ser absorvente. Isso provavelmente reduziu a quantidade de óleo sobre a superfície da semente, permitindo maior absorção de água no processo de germinação, diferentemente da embalagem tipo pet que apresenta como característica a impermeabilidade.
A redução e ausência de germinação observada nos tratamentos armazenados em embalagem pet pode ser explicada pelo fato de este tipo de embalagem não permitir a saída de possíveis gases voláteis que se formaram após o tratamento das sementes com os óleos essenciais, os quais podem ser fitotóxicos às sementes. Os óleos essenciais são misturas complexas de substâncias voláteis, lipofílicas, geralmente odoríferas e líquidas (SIMÕES; SPITZER, 2000).

Por serem mais sensíveis, os testes de vigor, como o de primeira contagem de germinação, por exemplo, são mais eficientes para avaliar possíveis efeitos negativos de óleos essenciais e extratos de plantas na germinação de sementes e crescimento de plântulas do que o teste de germinação (MARCOS FILHO, 2005).

Observa-se, na Tabela 3, o acúmulo de matéria seca em plantas de feijoeiro tratadas com diferentes óleos essenciais, tipo de embalagem e tempos de armazenamento. No tempo zero de armazenamento apenas o tratamento com $M$. officinalis apresentou redução no peso seco de plântulas, enquanto que, aos sessenta dias de armazenamento, apenas o tratamento com $M$. piperita. Aos cento e vinte dias de armazenamento menor acúmulo de matéria seca foi observado nos tratamentos com $M$. piperita e $C$. sinensis e, aos cento e oitenta dias, nos tratamentos com fungicida e testemunha. Estes resultados sugerem efeito fitotóxico de alguns óleos essenciais sobre as sementes de $P$. vulgaris.

No geral, nota-se um decréscimo no acúmulo de matéria seca das plântulas a partir dos cento e oitenta dias de armazenamento, que parece estar mais relacionado ao processo de envelhecimento das sementes do que ao efeito fitotóxico dos óleos essenciais utilizados, visto que esse processo também foi observado na testemunha.

Tabela 3. Acúmulo de matéria seca (g) em plantas de feijoeiro tratadas com diferentes óleos essenciais, tipo de embalagem e tempos de armazenamento.

\begin{tabular}{ccccc}
\hline \multicolumn{5}{c}{ Tempos de Armazenamento e Tipos de Embalagem } \\
\hline Tratamentos & 0 & 60 & 120 & 180 \\
\hline C. zeylanicum & $1,08 \mathrm{ABab}$ & $1,22 \mathrm{Aa}$ & $1,10 \mathrm{Aab}$ & $1,03 \mathrm{Ab}$ \\
C. aurantifolia & $0,94 \mathrm{ABa}$ & $1,08 \mathrm{ABa}$ & $0,99 \mathrm{ABCa}$ & $0,98 \mathrm{ABa}$ \\
C. sinensis & $1,14 \mathrm{Aa}$ & $1,10 \mathrm{ABa}$ & $0,85 \mathrm{Cb}$ & $0,91 \mathrm{ABCb}$ \\
C. citratus & $1,08 \mathrm{ABa}$ & $1,23 \mathrm{Aa}$ & $1,12 \mathrm{Aa}$ & $0,88 \mathrm{ABCb}$ \\
M. officinalis & $0,92 \mathrm{Bb}$ & $1,17 \mathrm{Aa}$ & $1,00 \mathrm{ABCab}$ & $0,92 \mathrm{ABb}$ \\
M. piperita & $1,00 \mathrm{ABa}$ & $0,92 \mathrm{Ba}$ & $0,89 \mathrm{BCa}$ & $0,88 \mathrm{ABCa}$ \\
S. aromaticum & $1,02 \mathrm{ABa}$ & $1,15 \mathrm{Aa}$ & $1,17 \mathrm{Aa}$ & $1,05 \mathrm{Aa}$ \\
Z. officinale & $0,95 \mathrm{ABbc}$ & $1,17 \mathrm{Aa}$ & $1,10 \mathrm{ABab}$ & $0,92 \mathrm{ABCc}$ \\
Fungicida & $1,09 \mathrm{ABa}$ & $1,07 \mathrm{Aba}$ & $1,03 \mathrm{ABCa}$ & $0,71 \mathrm{Cb}$ \\
Testemunha & $1,05 \mathrm{ABab}$ & $1,16 \mathrm{Aa}$ & $0,98 \mathrm{ABCbc}$ & $0,81 \mathrm{BCc}$ \\
\hline CV\% & & & 7,51 &
\end{tabular}

Médias seguidas de mesma letra maiúscula na coluna e minúscula na linha não diferem entre si pelo teste de Tukey a 5\% de probabilidade.

O armazenamento de sementes constitui-se em um conjunto de procedimentos voltados à preservação de sua qualidade, no intuito de proporcionar-lhes um ambiente nos quais as mudanças fisiológicas e bioquímicas sejam mantidas em um nível aceitável, evitando perdas desnecessárias tanto no aspecto qualitativo como no quantitativo. No entanto, vale ressaltar que o processo de deterioração das sementes é inevitável, mesmo quando colocadas em ambientes adequados a sua preservação. A qualidade das sementes não melhora durante o armazenamento, portanto, sua qualidade inicial é de fundamental importância para a manutenção da germinação e do vigor (BONOME, 2006).

Em pesquisa envolvendo a sanidade e a germinação de variedades crioulas de P. vulgaris, Moura et al. (2017) avaliaram a eficiência do óleo essencial de Eugenia uniflora L. (Pitanga) na incidência de fungos e qualidade fisiológica das sementes. Os autores relataram que, nas maiores concentrações (2\%), houve redução significativa na 
incidência de Fusarium spp., entretanto, altas concentrações do óleo afetaram os atributos relacionados ao desenvolvimento das plântulas, indicando efeito fitotóxico.

Segundo Mesquita et al. (2017), os óleos essenciais tendem a possuir composição complexa e concentrada, o que contribui para justificar seu efeito mesmo em baixas concentrações e efeitos tóxicos em altas concentrações.

Ressalta-se que, ao final do armazenamento, o tratamento com fungicida foi o que apresentou menor acúmulo de matéria seca nas plântulas, indicando que o tratamento com este produto químico foi o que mais prejudicou a capacidade de transferência dos materiais de reserva dos cotilédones para o eixo embrionário das sementesPara o índice de velocidade de germinação (Tabela 4), nota-se que, aos sessenta dias de armazenamento em garrafa pet, os tratamentos com C. citratus, $M$. officinalis e $M$. piperita apresentaram as menores médias. Por outro lado, nas embalagens kraft as menores médias para esse parâmetro foram observadas nas sementes tratadas com fungicida, $M$. officinalis, S. aromaticum, C. citratus e C. zeylanicum, sendo o tratamento com $S$. aromaticum o mais prejudicial. Aos cento e vinte dias de armazenamento, pode-se observar que a testemunha e o tratamento com $Z$. officinale proporcionaram maiores médias de velocidade de emergência quando na embalagem pet, enquanto que os menores valores foram observados nos tratamentos com $C$. citratus e $C$. zeylanicum. $\mathrm{Na}$ embalagem kraft, os tratamentos que se destacaram positivamente foram os com fungicida, $M$. piperita e $C$. zeylanicum, e os mais afetados foram testemunha, $S$. aromaticum e $C$. sinensis. No sexto mês de armazenamento (180 dias) não houve diferença estatística entre os tratamentos.

Magalhães et al. (2013), em seus estudos, demonstraram que o óleo essencial de $C$. citratus reduziu a porcentagem e o índice de velocidade de germinação dos aquênios de Lactuca sativa (Alface) em comparação ao óleo essencial de Lippia sidoides (Alecrim-pimenta) sendo esse efeito mais pronunciado com o aumento da concentração do óleo. Souza et al. (2005), utilizando extrato de C. citratus, também observaram decréscimos na germinação e no índice de velocidade de germinação em sementes de L. sativa e Eruca sativa (Rúcula) com o aumento da concentração.

Em testes com extratos aquosos de $C$. citratus Dalmolin et al. (2012) verificaram que esses inibiram o percentual de germinação e a velocidade de germinação (IVG) das sementes de Bidens pilosa L. (Picão-preto), por outro lado, resultados observados por Araújo et al. (2012) mostraram que o tratamento com óleo essencial de Cymbopogon winterianus (Citronela) não interferiu na velocidade de germinação de sementes de Foeniculum vulgare (Funcho). Resultados semelhantes aos observados no presente trabalho foram obtidos por Coelho et al. (2007), o qual mostrou que o óleo essencial de $C$. zeylanicum nas concentrações de $0,5 \%, 1,0 \%$; $1,5 \%$ e $2 \%$ afetou o índice de velocidade de germinação em sementes de Cereus jamacaru (Mandacaru).

$\mathrm{O}$ efeito negativo do óleo de $M$. piperita no índice de velocidade de germinação das sementes de $P$. vulgaris, acondicionadas em pet por 2 e 4 meses, provavelmente tenha ocorrido devido à presença do composto pulegol no óleo, constituinte de comprovada toxicidade (MUCCIARELLI et al., 2001). Estudos de Shiraishi (2002) mostraram que a espécie Mentha pulegium L (Hortelãzinho) interferiu negativamente na germinação de sementes de L. sativa.

Tabela 4. Índice de velocidade de emergência (IVE) em sementes de feijoeiro tratadas com diferentes óleos essenciais, tipo de embalagem e tempos de armazenamento.

\begin{tabular}{|c|c|c|c|c|c|c|c|}
\hline \multicolumn{8}{|c|}{ Tempos de Armazenamento e Tipos de Embalagem } \\
\hline \multirow{2}{*}{ Tratamentos } & \multirow[t]{2}{*}{0} & \multicolumn{2}{|c|}{60} & \multicolumn{2}{|c|}{120} & \multicolumn{2}{|c|}{180} \\
\hline & & Pet & Kraft & Pet & Kraft & Pet & Kraft \\
\hline C. zeylanicum & $4,46 \mathrm{Aa}$ & $4,85 \mathrm{ABCa}$ & 4,29CDa & $2,03 \mathrm{BCb}$ & $5,97 \mathrm{Aa}$ & $4,30 \mathrm{Aa}$ & 4,63 Aa \\
\hline C. aurantifolia & $5,55 \mathrm{Aa}$ & $5,98 \mathrm{ABCa}$ & 7,01ABCa & $4,45 \mathrm{ABCa}$ & $4,61 \mathrm{ABa}$ & $4,86 \mathrm{Aa}$ & 6,06 Aa \\
\hline C. sinensis & 3,08 Aa & $7,95 \mathrm{ABa}$ & 6,76ABCDa & 2,98ABCa & $1,19 \mathrm{Ba}$ & $5,61 \mathrm{Aa}$ & $5,05 \mathrm{Aa}$ \\
\hline C. citratus & $3,62 \mathrm{Aa}$ & $4,37 \mathrm{BCa}$ & 3,95CDa & $0,63 \mathrm{Cb}$ & $3,56 \mathrm{ABa}$ & $2,85 \mathrm{Aa}$ & $2,89 \mathrm{Aa}$ \\
\hline M. officinalis & $2,63 \mathrm{Aa}$ & $3,50 \mathrm{Ca}$ & $4,98 \mathrm{CDa}$ & $3 \mathrm{ABCa}$ & 4,96ABa & $2,98 \mathrm{Aa}$ & 3,69 Aa \\
\hline M. piperita & $4,78 \mathrm{Aa}$ & $3,40 \mathrm{Cb}$ & $9,02 \mathrm{Aba}$ & $5,24 \mathrm{ABa}$ & 6,06 Aa & $3,80 \mathrm{Aa}$ & $5,33 \mathrm{Aa}$ \\
\hline S. aromaticum & $4,38 \mathrm{Aa}$ & $6,54 \mathrm{ABCa}$ & $3,00 \mathrm{Db}$ & $4,37 \mathrm{ABCa}$ & $1,51 \mathrm{Bb}$ & $6,14 \mathrm{Aa}$ & $5,33 \mathrm{Aa}$ \\
\hline Z. officinale & $3,82 \mathrm{Aa}$ & 6,61ABCa & $6,02 \mathrm{ABCDa}$ & 6,28 Aa & $3,46 \mathrm{ABb}$ & 4,49 Aa & 6,49 Aa \\
\hline Fungicida & 3,99 Aa & 8,69Aa & 5,15BCDb & $1,25 \mathrm{Cb}$ & 7,13 Aa & $3,60 \mathrm{Aa}$ & 3,67 Aa \\
\hline Testemunha & $2,82 \mathrm{Aa}$ & 7,89ABa & $9,21 \mathrm{Aa}$ & $6,58 \mathrm{Aa}$ & $1,41 \mathrm{Bb}$ & $6,13 \mathrm{Aa}$ & 4,87 $\mathrm{Aa}$ \\
\hline
\end{tabular}

Médias seguidas de mesma letra maiúscula na coluna e minúscula na linha (dentro do mesmo tempo em embalagens diferentes) não diferem entre si pelo teste de Tukey a $5 \%$ de probabilidade.

Nas sementes de P. vulgaris incubadas por meio do método de blotter test foram observadas a presença de fungos do gênero Aspergillus spp., Penicillium spp. (Tabelas 5 e 7), que são considerados fungos de armazenamento produtores de micotoxinas, que ocasionam a deterioração das sementes (SOUZA et al., 2007), Fusarium spp. (Tabela 6), Cladosporium spp. e Neurospora spp. sendo os dois últimos em baixas quantidades (dados não apresentados). Além disso, observou-se também a incidência de bactérias nos diferentes tratamentos (Tabela 8).

$\mathrm{Na}$ Tabela 5, que apresenta a incidência do fungo Aspergillus spp. nas sementes de $P$. vulgaris, observa-se que antes do armazenamento não houve diferença significativa entre os tratamentos, exceção para o tratamento com 
fungicida que reduziu a porcentagem do fungo. No entanto, aos sessenta e cento e vinte dias de armazenamento, verificase incremento na incidência de fungos em todos os tratamentos, independentemente da embalagem utilizada, exceção para o tratamento com fungicida.

Aos sessenta dias de armazenamento, embora não tenha ocorrido diferença significativa para a maioria dos tratamentos, no geral a embalagem pet foi mais eficiente no controle do Aspergillus spp. do que a kraft, apresentando menor porcentagem de incidência do fungo. Merece destaque o tratamento em pet com M. officinalis que reduziu em $30 \%$ a incidência do Aspergillus spp. quando comparado com a embalagem kraft. Na embalagem pet, os melhores tratamentos alternativos foram com $C$. aurantifolia, $M$. officinalis, $S$. aromaticum e $M$. piperita, os quais reduziram a incidência do fungo em 26;23; 19 e $10 \%$ em relação à testemunha, respectivamente.

Aos cento e vinte dias de armazenamento, a incidência de fungo nos tratamentos não diferiu da testemunha, exceção para o fungicida, com menor porcentagem de Aspergillus spp. Aos 6 meses de armazenamento, nas embalagens pet pode-se verificar que a $C$. zeylanicum se igualou ao fungicida, inibindo o Aspergillus spp., já nas embalagens de sacos kraft apenas o fungicida se diferiu estatisticamente dos demais tratamentos, não apresentando o fungo.

Viegas et al. (2005) verificaram resultados positivos quanto ao uso do óleo essencial de $C$. zeylanicum, com maior inibição in vitro do desenvolvimento micelial de A. flavus. Segundo Bakkalia et al. (2008), as propriedades antimicrobianas dos óleos essenciais devem-se a sua característica lipofítica, em que a interação entre o óleo e os lipídios da membrana celular influenciam em sua estrutura e permeabilidade. Biasi e Deschamps (2009) observaram que concentrações mínimas do óleo essencial das espécies de Thymus erioclayx e Thymus x-porlock atuaram na parede celular, membrana e organelas celulares do fungo A. niger, inibindo o seu desenvolvimento.

A ação antifúngica do óleo essencial de C. zeylanicum já é relatada em outros estudos. Montes-Belmont e Carvajal (1998) demonstraram que a adição do óleo de C. zeylanicum em sementes de milho contendo A. flavus inibiu o desenvolvimento do fungo e que os dois constituintes do óleo, cinamaldeído e eugenol, também apresentaram propriedades inibitórias contra o patógeno. Jham et al. (2005) realizaram um estudo com o objetivo de identificar o principal composto fungitóxico da casca de C. zeylanicum sobre A. flavus e A. ruber e verificaram que o cinamaldeído é o principal composto com atividade antifúngica tanto no óleo extraído com hexano quanto no óleo destilado da casca de $C$. zeylanicum. Os outros componentes parecem ter efeito aditivo ou sinérgico na atividade fungitóxica total.

López et al. (2005) analisaram a atividade antimicrobiana dos óleos essenciais de $C$. zeylanicum e $S$. aromaticum sobre microrganismos contaminantes de alimentos e observaram que ambos os óleos apresentaram ação antibacteriana e antifúngica. Por outro lado, Alves et al. (2004) avaliando a composição química do óleo essencial de C. zeylanicum encontraram como componente majoritário o ácido cinâmico, o qual, segundo Simões \& Spitzer (1999), pode ser responsável pela inibição da germinação e do crescimento de plantas.

Tabela 5. Porcentagem de incidência de Aspergillus spp. em sementes de $P$. vulgaris tratadas com diferentes óleos essenciais, tipo de embalagem e tempos de armazenamento.

\begin{tabular}{|c|c|c|c|c|c|c|c|}
\hline \multicolumn{8}{|c|}{ Tempos de Armazenamento e Tipos de Embalagem } \\
\hline \multirow{2}{*}{ Tratamentos } & \multirow[t]{2}{*}{0} & \multicolumn{2}{|c|}{60} & \multicolumn{2}{|c|}{120} & \multicolumn{2}{|c|}{180} \\
\hline & & Pet & Kraft & Pet & Kraft & Pet & Kraft \\
\hline C. zeylanicum & $3,94 \mathrm{ABa}$ & $7,47 \mathrm{ABa}$ & $6,85 \mathrm{Ba}$ & $7,25 \mathrm{Aa}$ & $6,18 \mathrm{Aa}$ & $0,50 \mathrm{Bb}$ & $5,87 \mathrm{Aa}$ \\
\hline C. aurantifolia & $3,26 \mathrm{ABa}$ & $4,79 \mathrm{Ca}$ & $5,82 \mathrm{Ba}$ & $6,26 \mathrm{Aa}$ & $6,23 \mathrm{Aa}$ & $5,10 \mathrm{Aa}$ & $6,23 \mathrm{Aa}$ \\
\hline C. sinensis & $3,89 \mathrm{ABa}$ & $6,42 \mathrm{ABCa}$ & $6,11 \mathrm{Ba}$ & $5,57 \mathrm{Aa}$ & $7,05 \mathrm{Aa}$ & $5,36 \mathrm{Ab}$ & $7,05 \mathrm{Aa}$ \\
\hline C. citratus & $4,09 \mathrm{ABa}$ & $6,45 \mathrm{ABCa}$ & $6,30 \mathrm{Ba}$ & $6,45 \mathrm{Aa}$ & 7,42Aa & $6,45 \mathrm{Aa}$ & 7,42Aa \\
\hline M. officinalis & $4,01 \mathrm{ABa}$ & $4,98 \mathrm{Cb}$ & $7,13 \mathrm{Ba}$ & 6,41Aa & 6,54Aa & 4,73Aa & 5,51Aa \\
\hline M. piperita & $4,04 \mathrm{ABa}$ & $5,85 \mathrm{BCa}$ & $7,14 \mathrm{Ba}$ & 7,53Aa & 6,77Aa & 5,13Aa & $5,27 \mathrm{Aa}$ \\
\hline S. aromaticum & $3,83 \mathrm{ABa}$ & $5,24 \mathrm{BCa}$ & $6,02 \mathrm{Ba}$ & $6,26 \mathrm{Aa}$ & 7,34Aa & $6,26 \mathrm{Aa}$ & 7,34Aa \\
\hline Z. officinale & $3,53 \mathrm{ABa}$ & $8,32 \mathrm{Aa}$ & $6,95 \mathrm{Ba}$ & $5,35 \mathrm{Aa}$ & 6,50Aa & $6,93 \mathrm{Aa}$ & $6,66 \mathrm{Aa}$ \\
\hline Fungicida & 1,76Ba & $0,00 \mathrm{Da}$ & $0,00 \mathrm{Aa}$ & $1,20 \mathrm{Ba}$ & $1,56 \mathrm{Ba}$ & $0,50 \mathrm{Ba}$ & $0,00 \mathrm{Ba}$ \\
\hline Testemunha & $4,71 \mathrm{Aa}$ & $6,50 \mathrm{ABCa}$ & $7,56 \mathrm{Ba}$ & 6,43Aa & 6,48Aa & $6,43 \mathrm{Aa}$ & $6,48 \mathrm{Aa}$ \\
\hline CV\% & & & & 37,03 & & & \\
\hline
\end{tabular}

Médias seguidas de mesma letra maiúscula na coluna e minúscula na linha (dentro do mesmo tempo em embalagens diferentes) não diferem entre si pelo teste de Tukey a $5 \%$ de probabilidade.

Para o Fusarium spp. observa-se, no tempo zero de armazenamento, que apenas o tratamento com fungicida reduziu a incidência do patógeno (Tabela 6). Após sessenta e cento e vinte dias de armazenamento das sementes, nenhum tratamento se mostrou eficiente no controle do fungo. Por outro lado, aos cento e oitenta dias de armazenamento, o tratamento com os óleos essenciais de $C$. sinensis e $C$. citratus contribuiu para a redução da incidência de Fusarium spp. Superando, inclusive, o tratamento com fungicida. Todavia, os tratamentos com $M$. piperita e $M$. officinalis favoreceram a incidência do patógeno quando comparado a testemunha.

Quanto à embalagem, é possível observar que, no geral, as sementes tratadas e armazenadas em sacos kraft tiveram uma incidência menor do Fusarium spp.

As espécies do gênero Citrus apresentam propriedades comprovadas no controle de fitopatógenos, apresentando como seu componente principal o limoneno (MOREIRA et al., 2006; SHARMA; TRIPATHI, 2006). Pesquisa realizada por Phillips; Laird e Allen (2012) também demonstrou efeito 
promissor do óleo essencial de Citrus em sementes armazenadas ao longo de 10 dias, com redução no crescimento de A. niger e $P$. chrysogenum de 50 e $60 \%$, respectivamente.

Na literatura, encontra-se trabalhos que demonstraram a capacidade de alguns óleos essenciais em inibir o desenvolvimento micelial de F..oxysporum. Salgado et al. (2003) observaram in vitro a redução do crescimento micelial de $F$. oxysporum sob a ação dos óleos essenciais de Corymbia citriodora, Eucalyptus urophyla e Eucalyptus camaldulensis, na concentração de $500 \mathrm{mg} / \mathrm{Kg}$. Conforme mencionam Santos et al. (2007) em pesquisa, quando utilizado o óleo essencial de $S$. aromaticum, na concentração de $500 \mathrm{mg} / \mathrm{kg}$, observouse inibição total do crescimento fúngico.

A pesquisa realizada por Gonçalves et al. (2009), avaliando o efeito de óleos essenciais e extratos hidroalcoólicos de plantas medicinais na sanidade e na germinação de sementes de Glycine max (Soja), demonstrou a atividade antifúngica dos óleos de $Z$. officinale na inibição de Fusarium spp. Nas sementes tratadas com óleo essencial de C. aurantifolia, os autores observaram redução na incidência do patógeno para $0,5 \%$ em comparação a testemunha de $15 \%$ de sementes infestadas.

Tabela 6. Porcentagem de incidência de Fusarium spp. em sementes de feijoeiro tratadas com diferentes óleos essenciais, tipo de embalagem e tempos de armazenamento.

\begin{tabular}{|c|c|c|c|c|c|c|c|}
\hline \multicolumn{8}{|c|}{ Tempos de Armazenamento e Tipos de Embalagem } \\
\hline \multirow{2}{*}{ Tratamentos } & 0 & \multicolumn{2}{|c|}{60} & \multicolumn{2}{|c|}{120} & \multicolumn{2}{|c|}{180} \\
\hline & & Pet & Kraft & Pet & Kraft & Pet & Kraft \\
\hline C. zeylanicum & $4,39 \mathrm{ABa}$ & $3,88 \mathrm{Aa}$ & $1,99 \mathrm{Ab}$ & $2,63 \mathrm{Aa}$ & $0,85 \mathrm{Aa}$ & $4,12 \mathrm{BCDa}$ & $2,07 \mathrm{CDb}$ \\
\hline C. aurantifolia & 4,63 Aa & $1,31 \mathrm{Aa}$ & 2,28Aa & 2,70Aa & 2,57Aa & $5,16 \mathrm{ABCa}$ & $2,57 \mathrm{CDb}$ \\
\hline C. sinensis & $3,67 \mathrm{ABa}$ & $2,96 \mathrm{Aa}$ & $3,95 \mathrm{Aa}$ & $2,02 \mathrm{Aa}$ & $1,83 \mathrm{Aa}$ & $2,17 \mathrm{Da}$ & $1,83 \mathrm{Da}$ \\
\hline C. citratus & $4,03 \mathrm{ABa}$ & $2,18 \mathrm{Aa}$ & 3,17Aa & $2,18 \mathrm{Aa}$ & 3,43Aa & $2,18 \mathrm{Da}$ & $3,43 \mathrm{BCDa}$ \\
\hline M. officinalis & 5,51 Aa & 3,85 Aa & $1,99 \mathrm{Ab}$ & 3,22Aa & 3,02Aa & $6,22 \mathrm{ABa}$ & $4,67 \mathrm{ABCa}$ \\
\hline M. piperita & 4,73 Aa & $2,44 \mathrm{Aa}$ & $2,22 \mathrm{Aa}$ & $2,07 \mathrm{Aa}$ & 2,20Aa & 7,55Aa & $6,06 \mathrm{ABa}$ \\
\hline S. aromaticum & $4,07 \mathrm{ABa}$ & $4,05 \mathrm{Aa}$ & $2,07 \mathrm{Ab}$ & 4,50Aa & $2,36 \mathrm{Ab}$ & 4,50BCDa & $2,36 \mathrm{CDb}$ \\
\hline Z. officinale & $5,04 \mathrm{Aa}$ & 3,37Aa & $3,05 \mathrm{Aa}$ & $2,06 \mathrm{Aa}$ & 1,20Aa & $2,63 \mathrm{CDb}$ & 6,55 Aa \\
\hline Fungicida & $1,76 \mathrm{Ba}$ & $2,70 \mathrm{Aa}$ & $2,76 \mathrm{Aa}$ & $1,86 \mathrm{Aa}$ & 3,12Aa & $4,12 \mathrm{BCDb}$ & 6,98Aa \\
\hline Testemunha & $4,87 \mathrm{Aa}$ & $2,50 \mathrm{Aa}$ & 3,58Aa & 2,69Aa & 2,60Aa & 2,69CDa & $2,60 \mathrm{CDa}$ \\
\hline $\mathrm{CV} \%$ & & & & 36,36 & & & \\
\hline
\end{tabular}

Médias seguidas de mesma letra maiúscula na coluna, e minúscula na linha (dentro do mesmo tempo em embalagens diferentes) não diferem entre si pelo teste de Tukey a $5 \%$ de probabilidade.

No tempo zero de armazenamento nota-se que os tratamentos com fungicida e com óleo essencial de $S$. aromaticum foram os únicos eficientes em reduzir a incidência de Penicillium spp. das sementes (Tabela 7). Aos sessenta dias de armazenamento, as sementes tratadas com fungicida mantiveram menor incidência do patógeno, seguido do tratamento com óleo essencial de $S$. aromaticum e $C$. zeylanicum que apresentaram uma redução de 42 e $31 \%$ da incidência de Penicillium spp. para a embalagem pet em relação à testemunha. $\mathrm{Na}$ embalagem kraft não houve diferença estatística entre os tratamentos, exceção para o tratamento com fungicida que inibiu quase que completamente a incidência do patógeno. Aos cento e vinte dias de armazenamento, os tratamentos com $M$. piperita, $M$. officinalis, C. zeylanicum, C. sinensis e $S$. aromaticum apesar de não terem diferido da testemunha, também não diferiam do tratamento fungicida nas embalagens pet. Aos cento e oitenta dias, houve diferença para o fungicida em ambas as embalagens, sendo que, na garrafa pet, o óleo essencial de $C$. zeylanicum não se diferiu do tratamento fungicida.

No geral, a embalagem pet foi mais eficiente para controlar o Penicillium spp. (Tabela 7) e o Aspergillus spp. (Tabela 5). O maior controle de patógenos pelo pet pode ser atribuído à característica impermeável da embalagem, evitando a saída dos gases voláteis, com princípios ativos contra os patógenos, liberados pelos óleos essenciais. Além disso, este tipo de embalagem não permite a troca de vapor de água com o ambiente, impedindo o aumento da umidade das sementes conforme oscilação da umidade relativa do ar do ambiente de armazenamento. Ambientes úmidos favorecem a proliferação de fungos de armazenamento.

Pesquisa realizada por Boukaew et al (2017) demonstraram a atividade antifúngica in vitro do óleo essencial de $S$. aromaticum na concentração de $100 \mu 1.1^{-1}$, com inibição da germinação de esporos de A. flavus de $84,7 \%$. Os mesmos autores verificaram que, em sementes de milho, o óleo essencial de $S$. aromaticum na concentração de $10 \mu .1^{-1}$, promoveu inibição total do patógeno.

Khan e Ahmad (2011) avaliaram os óleos essenciais de Cinnamomum verum (caneleira-verdadeira), S. aromaticum, C. citratus e Cymbopogon martini e seus principais componentes, cinamaldeído, eugenol, citral e geraniol, respectivamente, sobre o crescimento de A. fumigatus. Inibição máxima $(97,31 \%)$ foi obtida com o componente geraniol sobre crescimento do patógeno. A atividade antifúngica do óleo essencial da espécie Cymbopogon winterianus também foi investigada por Souza et al. (2005) sobre os gêneros de fungos Aspergillus spp., Rhizopus spp., Penicillium spp. e Fusarium spp., sendo verificado efeito inibitório sobre os patógenos apenas na concentração pura do óleo.

Teixeira (2010), testando diferentes óleos essenciais sobre o fungo Stenocarpella maydis inoculado artificialmente em sementes de Zea mays, verificou que houve menor incidência do patógeno em sementes tratadas com o óleo essencial de C. zeylanicum (28\%), seguido pelo óleo de $S$. aromaticum (39\%), o qual não diferiu estatisticamente do fungicida $(40 \%)$. 
No óleo essencial de C. citratus, Gonçalves et al. (2009) constataram altos teores do componente geranial (46,32\%) e neral $(31,28 \%)$, sendo a mistura destes dois componentes denominada de citral. Neste sentido, pode-se atribuir a menor incidência de Penicillium spp. nas sementes de $P$. vulgaris armazenadas à presença desses componentes no óleo.

Souza et al. (2007) comprovaram o efeito antifúngico do extrato de $C$. citratus na inibição do desenvolvimento do fungo $F$. proliferatum, reduzindo a incidência de tombamento e podridão do colmo em plântulas de Zea mays, e aumentando a germinação de suas sementes. A eficácia do óleo essencial de $C$. zeylanicum também foi comprovada pela inibição total do crescimento micelial do fungo A. parasiticus, a partir da concentração de 0,25 $\mu \mathrm{L} / \mathrm{ml}$ (FREIRE, 2008).

Tabela 7. Porcentagem de incidência de Penicillium spp. em sementes de feijoeiro tratadas com diferentes óleos essenciais, tipo de embalagem e tempos de armazenamento.

\begin{tabular}{|c|c|c|c|c|c|c|c|}
\hline \multicolumn{8}{|c|}{ Tempos de Armazenamento e Tipos de Embalagem } \\
\hline \multirow{2}{*}{ Tratamentos } & 0 & \multicolumn{2}{|c|}{60} & \multicolumn{2}{|c|}{120} & \multicolumn{2}{|c|}{180} \\
\hline & & Pet & Kraft & Pet & Kraft & Pet & Kraft \\
\hline C. zeylanicum & 7,04ABCa & $5,35 \mathrm{Ba}$ & $4,60 \mathrm{Aa}$ & $5,27 \mathrm{ABa}$ & $5,51 \mathrm{ABa}$ & $1,36 \mathrm{Bb}$ & $5,55 \mathrm{Aa}$ \\
\hline C. aurantifolia & 7,79ABa & 7,79Aa & $6,42 \mathrm{Aa}$ & $6,28 \mathrm{Aa}$ & $6,05 \mathrm{Aa}$ & $5,63 \mathrm{Aa}$ & $6,05 \mathrm{Aa}$ \\
\hline C. sinensis & $7,15 \mathrm{ABCa}$ & $6,02 \mathrm{ABa}$ & $4,61 \mathrm{Aa}$ & $5,18 \mathrm{ABa}$ & 5,99Aa & $5,03 \mathrm{Aa}$ & $5,99 \mathrm{Aa}$ \\
\hline C. citratus & 7,39ABCa & $5,60 \mathrm{ABa}$ & $6,49 \mathrm{Aa}$ & 5,60Aa & $5,25 \mathrm{ABa}$ & $5,60 \mathrm{Aa}$ & $5,25 \mathrm{Aa}$ \\
\hline M. officinalis & $5,66 \mathrm{BCa}$ & $5,52 \mathrm{ABa}$ & 6,69Aa & $5,19 \mathrm{ABb}$ & 6,65Aa & $5,44 \mathrm{Ab}$ & 6,99Aa \\
\hline M. piperita & $6,33 \mathrm{ABCa}$ & $6,57 \mathrm{ABa}$ & $6,73 \mathrm{Aa}$ & $5,50 \mathrm{ABa}$ & $5,86 \mathrm{Aa}$ & 4,64Aa & $5,87 \mathrm{Aa}$ \\
\hline S. aromaticum & $5,43 \mathrm{Ca}$ & $4,46 \mathrm{Ba}$ & $5,75 \mathrm{Aa}$ & $4,43 \mathrm{ABb}$ & 6,30Aa & $4,43 \mathrm{Ab}$ & $6,30 \mathrm{Aa}$ \\
\hline Z. officinale & $8,02 \mathrm{Aa}$ & $5,93 \mathrm{ABa}$ & 6,30Aa & $5,53 \mathrm{Aa}$ & $6,14 \mathrm{Aa}$ & $5,27 \mathrm{Aa}$ & $5,32 \mathrm{Aa}$ \\
\hline Fungicida & $1,06 \mathrm{Da}$ & $0,00 \mathrm{Ca}$ & $0,50 \mathrm{Ba}$ & $3,15 \mathrm{Ba}$ & $3,39 \mathrm{Ba}$ & $1,36 \mathrm{Ba}$ & $0,00 \mathrm{Ba}$ \\
\hline Testemunha & 7,42ABCa & 7,79Aa & $5,81 \mathrm{Ab}$ & $6,44 \mathrm{Aa}$ & $5,92 \mathrm{Aa}$ & $6,44 \mathrm{Aa}$ & $5,51 \mathrm{Aa}$ \\
\hline CV\% & & & & 18,69 & & & \\
\hline
\end{tabular}

Médias seguidas de mesma letra maiúscula na coluna e minúscula na linha (dentro do mesmo tempo em embalagens diferentes) não diferem entre si pelo teste de Tukey a $5 \%$ de probabilidade.

Quanto à presença de bactérias nas sementes (Tabela 8), nota-se que, no geral, todos os tratamentos favoreceram a incidência do patógeno, entretanto, o tratamento com fungicida foi o que promoveu maior incremento nas bactérias. Em relação às embalagens de armazenamento, na maior parte dos tratamentos não se verificou diferença estatística entre elas. Chao et al. (2000), avaliando a atividade antimicrobiana de óleos essenciais, constataram que o óleo essencial de $M$. spicata contém propriedades antifúngica e antibacteriana. Lima et al. (2006) identificaram, em seu trabalho, efeitos satisfatórios do uso de C. zeylanicum e Peumus boldus (Boldo do chile) na atividade contra Candida sp., visto que ambos os óleos inibiram $58 \%$ do crescimento das cepas.

Trajano e colaboradores (2009) testaram os óleos essenciais de C. zeylanicum, Coriandrum sativum (Coentro),
Cuminum cyminum (Cominho), S. aromaticum, M. piperita, Ocimum basilicum, Origanum majorana (Manjerona), Pimpinella anisum (Erva-doce), Piper nigrum (Pimenta do reino), Rosmarinus officinalis (Alecrim) e Z. officinale no controle de bactérias contaminantes de alimentos, os resultados indicaram que os 11 óleos essenciais, com exceção do $P$. nigrum, apresentaram atividades antibacterianas. Esses resultados diferem dos observados no presente trabalho, em que, na maioria dos tratamentos, notou-se aumento na incidência de bactérias, exceção para o tratamento com $C$. zeylanicum aos sessenta dias de armazenamento em embalagem kraft em que a incidência do patógeno foi reduzida.

Tabela 8. Porcentagem de incidência de bactérias em sementes de P. vulgaris L. tratadas com diferentes óleos essenciais, tipo de embalagem e tempos de armazenamento.

\begin{tabular}{cccccccc}
\hline \multicolumn{7}{c}{ Tempos de Armazenamento e Tipos de Embalagem } \\
\hline \multirow{2}{*}{ Tratamentos } & 0 & \multicolumn{2}{c}{60} & \multicolumn{2}{c}{120} & Kraft & Pet \\
\cline { 2 - 7 } & & Pet & Kraft & Pet & Kraft \\
\hline C. zeylanicum & $5,75 \mathrm{ABa}$ & $4,10 \mathrm{ABa}$ & $1,06 \mathrm{Bb}$ & $2,38 \mathrm{Aa}$ & $2,93 \mathrm{ABa}$ & $4,74 \mathrm{ABa}$ & $2,75 \mathrm{BCDb}$ \\
C. aurantifolia & $4,64 \mathrm{ABa}$ & $1,49 \mathrm{Bb}$ & $3,54 \mathrm{Aba}$ & $3,30 \mathrm{Aa}$ & $0,50 \mathrm{Bb}$ & $5,36 \mathrm{Aa}$ & $0,50 \mathrm{Db}$ \\
C. sinensis & $4,13 \mathrm{ABa}$ & $3,35 \mathrm{ABa}$ & $4,02 \mathrm{Aba}$ & $3,44 \mathrm{Aa}$ & $2,16 \mathrm{ABa}$ & $3,24 \mathrm{ABCa}$ & $2,16 \mathrm{BCDa}$ \\
C. citratus & $5,76 \mathrm{ABa}$ & $2,67 \mathrm{ABb}$ & $4,96 \mathrm{Aa}$ & $2,67 \mathrm{Aa}$ & $2,63 \mathrm{ABa}$ & $2,67 \mathrm{ABCa}$ & $2,63 \mathrm{BCDa}$ \\
M. officinalis & $5,15 \mathrm{ABa}$ & $3,86 \mathrm{ABa}$ & $4,45 \mathrm{Aa}$ & $3,95 \mathrm{Aa}$ & $2,17 \mathrm{ABa}$ & $4,46 \mathrm{ABCa}$ & $3,67 \mathrm{ABCa}$ \\
M. piperita & $5,50 \mathrm{ABa}$ & $2,83 \mathrm{ABa}$ & $3,04 \mathrm{Aba}$ & $1,81 \mathrm{Aa}$ & $2,21 \mathrm{ABa}$ & $4,80 \mathrm{ABa}$ & $4,61 \mathrm{ABa}$ \\
S. aromaticum & $5,89 \mathrm{ABa}$ & $4,65 \mathrm{Aa}$ & $3,36 \mathrm{Aba}$ & $2,15 \mathrm{Aa}$ & $2,04 \mathrm{ABa}$ & $2,15 \mathrm{BCa}$ & $2,04 \mathrm{BCDa}$ \\
Z. officinale & $5,50 \mathrm{ABa}$ & $3,05 \mathrm{ABa}$ & $4,50 \mathrm{Aa}$ & $1,61 \mathrm{Aa}$ & $1,47 \mathrm{ABa}$ & $2,38 \mathrm{ABCa}$ & $3,72 \mathrm{ABCa}$ \\
Fungicida & $6,60 \mathrm{Aa}$ & $4,37 \mathrm{ABa}$ & $5,72 \mathrm{Aa}$ & $3,90 \mathrm{Aa}$ & $4,43 \mathrm{Aa}$ & $4,74 \mathrm{ABa}$ & $6,06 \mathrm{Aa}$ \\
Testemunha & $3,22 \mathrm{Ba}$ & $3,70 \mathrm{ABa}$ & $4,40 \mathrm{Aa}$ & $1,46 \mathrm{Aa}$ & $1,46 \mathrm{ABa}$ & $1,46 \mathrm{Ca}$ & $1,46 \mathrm{CDa}$ \\
\hline CV\% & & & & 36,57 & & &
\end{tabular}

Médias seguidas de mesma letra maiúscula na coluna e minúscula na linha (dentro do mesmo tempo em embalagens diferentes) não diferem entre si pelo teste de Tukey a $5 \%$ de probabilidade. 


\section{CONCLUSÕES}

Os tratamentos com óleos essenciais de C. aurantifolia e C. zeylanicum não afetam a porcentagem de germinação das sementes no decorrer do armazenamento quando acondicionadas em embalagem kraft.

A incidência de fitopatógenos em sementes de feijoeiro com a presença de Aspergillus spp. Fusarium spp. Penicillium spp. e bactérias. Os óleos essenciais de $C$. zeylanicum e $S$. aromaticum promovem menor incidência de Penicillium spp., ambos armazenados em pet, tendo o óleo essencial de $C$. zeylanicum resultado semelhante ao fungicida comercial.

A embalagem kraft é mais eficiente em preservar a qualidade fisiológica das sementes tratadas de Phaseolus vulgaris $\mathrm{L}$. do que a embalagem pet.

\section{REFERÊNCIAS}

ALMEIDA, F. de A. C.; FONSECA, K. S.; GOUVEIA, J. P. G. de. Armazenamento processamento de produtos agrícolas. Revista Brasileira de Engenharia Agrícola e Ambiental, Campina Grande, v.3, n. 2, p. 195-201, 1999.

ALVES, M. C. S.; MEDEIROS FILHO, S.; INECCO, R.; TORRES, S. B. Alelopatia de extratos voláteis na germinação de sementes e no comprimento da raiz de alface. Pesquisa Agropecuária Brasileira, v.39, n.11, p.1083-1086, 2004.

ARAUJO, A. N.; COSTA, P. A.; SOUZA, W.; MEDEIROS, J.; SANTOS, S. Atividade antifúngica do óleo essencial de citronela em sementes de Erva-doce (Foeniculum vulgare Mill.). Revista Verde, Mossoró, v.7, n.1, p. 189-195, 2012.

AZEVEDO, M. R. Q. A; GOUVEIA, J. P. G.; TROVÃO, D. M. M.; QUEIR, G. A. V. P. Influência das embalagens e condições de armazenamento no vigor de sementes de gergelim. Revista Brasileira de Engenharia Agrícola e Ambiental, v.7, n. 3, p. 519-524, 2003.

BAKKALIA, F.; AVERBECK, S.; AVERBECK, D.; IDAOMAR, M. Biological effects of essencial oils: a review. Food and Chemical Toxicology, v. 46, n.2, p. 446-475, 2008.

BONOME, L. T. S. Alteraçoes fisiólogicas, bioquimícas e moleculares em sementes de seringueira [Hevea brasiliensis (Willd. Ex Adr. de Juss) Müell.-Arg.] durante o armazenamento. Dissertação de Doutorado. Lavras: UFLA, 2006. p124.

BONOME, L. T. S.; OLIVEIRA, L. E. M.; GRACIANO, M. H. P.; MATTOS, J. O. S.; MESQUITA, A. C. Influência do tratamento fungicida e da temperatura sobre a qualidade fisiológica de sementes de seringueira durante o armazenamento. Agrarian, Dourados, v.2, n.5, p. 97-112, 2009.

BRASIL, 2009. Ministério da Agricultura, Pecuária e Abastecimento. Manual de Análise Sanitária de Sementes / Ministério da Agricultura, Pecuária e Abastecimento. Secretaria de Defesa Agropecuária. - Brasília: MAPA/ACS, 202p. A
BRASIL. 2009. Ministério da Agricultura, Pecuária e Abastecimento. Regras para análise de sementes. Secretaria de Defesa Agropecuária. Brasília: MAPA/ACS, 399p. B

BIASI, L. A.; DESCHAMPS, C. Plantas aromáticas: do cultivo à produção de óleo essencial. Curitiba: Layer Studio Gráfico e Editora Ltda, p. 160, 2009.

BOUKAEW, S.; POONSUKPRASERTSAN, P.; SATTAYASAMITSATHIT, S. Evaluation of antifungal activity of essential oils against aflatoxigenic Aspergillus flavus and their allelopathic activity from fumigation to protect maize seeds during storage Industrial Crops and Products, v. 97, p. 558-566, 2017.

BRAGANTINI, C. Alguns aspectos do armazenamento de sementes e grãos de feijão. Santo Antônio de Goiás: Embrapa Arroz e Feijão, p.28, 2005.

BROWN, P. D., MORRA, M. J., MCCAFFREY, J. P., AULD, D. L.; WILLIAMS III, L. Allelochemicals produced during glucosinolate degradation in soil. Journal of Chemical Ecology 17:2021-2034, 1991.

BROWN, P. D.; MORRA, M. J. Glucosinolate containing plant tissues as bioherbicides. Journal of Agricultural and Food Chemistry, v. 43, p.3070-3074, 1995.

CANEPELLE, M. A. B; CANEPPELE, C.; LÁZZARI, F. A.; LÁZZARI, S. M. N. Correlation between the infestation level of Sitophilus zeamais Motschulsky, 1855 (Coleoptera, Curculionidae) and the quality factors of stored corn, Zea mays L. (Poaceae). Revista Brasileira de Entomologia, v.47, p.625-630, 2003.

CATAO, H. C. M. Termotolerância na germinação e no armazenamento de sementes de alface. 2015. p.91. Dissertação (Doutorado em Produção Vegetal)- Universidade Federal de Lavras, Lavras, 2013.

CHAO, D.; FARMER D. F; SEVICK M. A; ESPEKAND, M. A; VITOLINS, M., NAUGHTON, M. J. O valor do atendimento da sessão em uma intervenção de perda de peso. American Journal of Health Behavior. 2000. p413-421.

COELHO, M. S. E.; BRITO, N. M.; NASCIMENTO, L. C.; ALVES, E.U. Efeito de óleos essenciais sobre a germinação de sementes de mandacaru. In: Jornada Universitária da Unidade Academica de Garanhuns, Garanhuns: Universidade Federal Rural de Pernambuco/ Unidade Acadêmica de Garanhuns. 2007.

COMPANHIA NACIONAL DE ABASTECIMENTO. Acompanhamento da safra brasileira de grãos - v. 5 Safra 2017/18 - Primeiro levantamento, Brasília: Conab, p. 1-114 2017.

COSTA, G. E. A., QUEIROZ-MONICI, K. S., REIS, M. S. P. M., OLIVEIRA, A. C. Chemical composition, dietary fibre and resistant starch contents of raw and cooked pea, common bean, chikpea and lentil legumes. Food Chemistry, v. 94, p.327-330, 2006. 
CUNHA, R. P. da.; CORRÊA, M. F.; SCHUCHL, O. B.; OLIVEIRA, R. C. de.; JUNIOR, J. de. S. A.; SILVA, J. D. G. da; ALMEIDA, T. L. de. Diferentes tratamentos de sementes sobre o desenvolvimento de plantas de soja. Ciência Rural, Santa Maria , v. 45, n. 10, p. 1761-1767, 2015.

DALMOLIN, S. F.; PERSEL, C.; CRUZ-SILVA, T. A. da Alelopatia de capim-limão e sálvia sobre a germinação de picão preto. Cultivando Saber, v.5, n.3, p.176-189, 2012.

DOMENE, M. P.; GLÓRIA, E. M.; BIAGI, J. D.; BENEDETTI, B. C.; MARTINS, L. Efeito do tratamento com óleos essenciais sobre a qualidade fisiológica e sanitária das sementes de milho (Zea mays). Arquivos do Instituto Biológico, São Paulo, v.83, 1-6, 2016.

DUDAI, N.; POLJAKOFF-MAYBER, A.; MAYER, A. M.; PUTIEVSKY, E.; LERNER, H. R. Essential oils as allelochemicals and their potential use as bioherbicides. Journal of Chemical Ecology, v.25, p.1079-89, 1999.

FERRÃO, J. E. M. Especiarias: cultura, tecnologia, comércio. Instituto de Investigação Tropical: Lisboa, p.413, 1993.

FERREIRA, D. F. Sisvar: um sistema de análise estatística de computador. Ciência Agrotecnologia, Lavras, v. 35, n. 6, p. 1039-1042, 2011.

FREIRE, J. M. Óleos essenciais de canela, manjerona e anisestrelado: caracterização química e atividade biológica sobre $S$ aureus, E. coli e Aspergillus flavus e Aspergillus parasiticus. Dissertação (Mestrado em Agroquímica) Universidade Federal de Lavras, UFLA, Lavras, p.68, 2008.

GHINI, R.; KIMATI, H. Resistência de fungos a fungicidas. $1^{\text {a }}$ edição. Jaguariúna: Embrapa Meio Ambiente, p78, 2000.

GOMES, R. S. S; NUNES, M. C; NASCIMENTO, L. C.; SOUZA, J. O.; PORCINO, M. M. Eficiência de óleos essenciais na qualidade sanitária e fisiológica em sementes de feijão-fava (Phaseolus lunatus L.). Revista Brasileira de Plantas Medicinais, v.18, n.1, p.279-287, 2016.

GONÇALVES G. G.; MATTOS L. P. V.; MORAIS, L. A. S. Óleos essenciais e extratos vegetais no controle de fitopatógenos de grãos de Óleos essenciais e extratos vegetais no controle de fitopatógenos de grãos de soja. Horticultura Brasileira 27, p.102-107, 2009.

IAPAR. Produção de sementes em pequenas propriedade/ coord. Alberto Sergio Barros. $2^{\mathrm{a}}$ ed. Rev. Ampl. Londrina: IAPAR. Circular técnica, 129. p.98, 2007.

JARDINETTI, V. A.; CRUZ M. E. da S.; MAIA, A. J.; OLIVEIRA, J.S.B.; SANTOS, E. M. dos. Efeito de óleos essenciais no controle de patógenos na germinação de sementes de milho (Zea mays). In: VII Encontro Internacional de Produção Científica, Maringá - PR, 25-28, 2011.

JHAM, G. N.; DHINGRA, O. D.; JARDIM, C. M.; VALENTE, V. M. Identification of the major fungitoxic component of Cinnamon bark oil. Fitopatologia Brasileira, v.30, n.4, p.404-408. 2005.
KHAN, M. S. A.; AHMAD, I. In vitro antifungal, antielastase and anti-keratinase activity of essential oils of Cinnamomum, Syzygium- and Cymbopogon-species against Aspergillus fumigatus and Trichophyton rubrum. Phytomedicine, v. 19, n.1, p. 48-55, 2011.

LEMES, E. S. ASSIS, D. B. de.; TAVARES, L. C.; JUNIOR, J. C. B.; OLIVEIRA, S. de.; TUNES, L. M.; MENEGHELlO, G. E. Qualidade fisiológica e sanitária de sementes de soja tratadas com essência de suco de laranja. Tecnologia \& Ciência Agropecuária, João Pessoa, v.10, n.2, p.74-82, 2016.

LIMA, I. O; OLIVEIRA, R. A. G; LIMA, E. O; FARIAS, PN. M. P; SOUZA, E. L. Atividade antifúngica de óleos essenciais sobre espécies de Candida. Revista Brasileira Farmacognosia., João Pessoa , v. 16, n. 2, p. 197-201, 2006 .

LÓPEZ, P; SANCHEZ, C; BATTLE, R; NERIN, C. Solidand vapor-phase antimicrobial activities of six essential oils: susceptibility of selected foodborne bacterial and fungal strains. Journal of Agricultural and Food Chemistry, v. 53, n.17, p. 6939-6946, 2005.

LORENZI, H.; MATOS, F. J. A. Plantas medicinais no Brasil: nativas e exóticas. Nova Odessa. São Paulo: Editora Plantarum, p. 544, 2002.

MAGALHÃES, H. M.; AQUINO, C. F.; SOARES, E. P. S.; SANTOS, L. D. T. S.; LOPES, P. S. N. Allelopathic action essential oils of alecrim-pimenta and lemongrass in germination of lettuce achenes. Semina: Ciências Agrárias, Londrina, v. 34, n. 2, p. 485-496, 2013.

MAGUIRE, J. D. Speed germination-aid in selection and evaluation for seedling emergence and 102 vigor. Crop Science. Madison, v. 2, p. 176-177, 1962

MARASCHIN-SILVA, F. Extração aquosa de aleloquímicos e bioensaios laboratoriais de alelopatia. 2004. 87 p. Dissertação (Mestrado) - Instituto de Biociências, Universidade Federal do Rio Grande do Sul, 2004.

MARCOS FILHO, J. Fisiologia de sementes de plantas cultivadas. FEALQ, Piracicaba, p. 465, 2005.

MATA M. F.; ARAÚJO E.; NASCIMENTO, L. C.; SOUZA A. E. F.; VIANA, S. Incidência e controle alternativo de patógenos em sementes de mandacaru (Cereus jamacaru DC, Cactaceae). Revista brasileira de Biociências, v.7, n.4, p.327334, 2009.

MESQUITA, P. R. R.; NUNES, E. C.; SANTOS, F. N.; BASTOS, L. P.; COSTA, M. A. P. C.; RODRIGUES, F. de.; ANDRADE, J. B. de. Discrimination of Eugenia uniflora L. biotypes based on volatile compounds in leaves using HSSPME/GC-MS and chemometric analysis. Microchemical Journal, v.130, p.79-87, 2017.

MONTES-BELMONT R.; CARVAJAL M. Control of Aspergillus flavus in maize with plant essential oils and their 
components. Journal of Food Protection, v.6, p. 616-619, 1998.

MONDEGO, J. M; MELO, P. A. F. R; PINTO, K. M. S.; NASCIMENTO, L. C; ALVES, E. U.; BATISTA, J. L. Controle alternativo da microflora de sementes de Pseudobombax marginatum com óleo essencial de copaíba (Copaifera sp.). Bioscience Journal, v.30, n.2, p.349-355, 2014.

MOREIRA, M. D.; PICANÇO, M. C; SILVA, E. M; MORENO, S. C; MARTINS, J. C. Uso de inseticidas botânicos no controle de pragas. Em M. VenzPaula Júnior, T. J. e A. Pallini (Eds.), Controle alternativo de pragas e doenças EPAMIG/ CTZM. Viçosa, p.86, 2006.

MOURA, G. S.; PIETROBELLI, S. R.; OLIVEIRA, I. M. R.de.; OLIVEIRA, I. J. de.; FRANZENER, G. Essential oil of surinam cherry in the germination and sanity of bean landrace varieties. Revista Brasileira de Agropecuária Sustentável (RBAS), v.7, n.3, p.48-55, 2017.

MUCCIARELLI, M.; CAMUSSO, W.; BERTEA, C. M.; MAFFEI, M. Effect of (+)-pulegone and other oil components of Mentha x piperita on cucumber respiration. Phytochemistry, v.57, n.1, p.91-8, 2001.

NAKAGAWA, J. Testes de vigor baseados no desempenho germinativo das plântulas. In: KRZYZANOWSKI, F. C.; VIEIRA, R. D.; FRANÇA-NETO, J. B. (Ed.). Vigor de sementes: conceitos e testes. Londrina: ABRATES, cap.2, p.1-24, 1999.

OLIVEIRA, J. A.; SILVA, T. T. de A.; PINHO, É. V. de R V.; ABREU, L. A. de S. Secagem e armazenamento de sementes de sorgo com alto e baixo teor de tanino. Revista Brasileira de Sementes, v.33, n.4 p.699-710, 2011.

OOTANI, M. A.; AGUIAR, R. W.; RAMOS, A. A. C.; BRITO, D. R.; SILVA, J. B. da; CAJAZEIRA, J. P.; J.Use of Essential Oils in Agriculture. Journal of Biotechnology and Biodiversity, v.4, p.162-174, 2013.

ORTIZ, E. L. The Encyclopedia of Herbs, Spices, and Flavourings. Dorling Kindersley Publishers, London, 1992.

PIERRE, R. O. Óleo essencial e extratos de cravo-da-índia no controle de Colletotrichum gloeosporioides, agente da mancha manteigosa, em sementes e mudas de café. Dissertação (Mestrado) - Universidade Federal de Lavras, p.79, 2009.

PHILLIPS, C. A.; LAIRD, K.; ALLEN, S. C. The use of Citri- $\mathrm{V}^{\mathrm{TM}}{ }_{\circledR}-\mathrm{An}$ antimicrobial citrus essential oil vapour for the control of Penicillium chrysogenum, Aspergillus niger and Alternaria alternata in vitro and on food. Food Research International, v. 47, n. 2, p. 310- 314, 2012.

POPINIGIS, F. Fisiologia da semente. 2.ed. Brasília: AGIPLAN, p.289, 1985.
RABELO, A. C. R; RIBEIRO, D. F; REZENDE, R. M; ALCANTRA, E; SOARES, A. F. Adubação nitrogenada na cultura do feijoeiro. Ciência Rural, v.36, n.4, 2006.

RAINA, V. K., SRIVASTAVA, S. K., AGGARWAL, K. K., SYAMASUNDAR, K. V.; KUMAR, S. Essential oil composition of Eugenia caryophyllata leaf from Little Andaman, India. Flavour Fragrance Journal, v. 16, p.334-336, 1992, 2001.

ROSSI, E.; COSIMI, S.; LONI, A. Bioactivity of essential oils from Mediterranean plants: Insecticidal properties on Sitophilus zea mays and effects on seed germination. Journal of Entomology, v.9, n.6, p.403-412, 2012.

SALGADO, A. P. S. P.; CARDOSO, M. G.; SOUZA, P. E.; SOUZA, J. A.; ABREU, C. M. P.; PINTO, J. E. B. P. Avaliação da atividade fungitóxica de óleos essenciais de folhas de Eucalyptus sobre Fusarium oxysporum, Botrytis cinerea e Bipolares sorokiniana. Ciência e Agrotecnologia, v.27, p.249, 2003.

SANTOS, L. G. M. dos.; CARDOSO, M. da.; LIMA, R. K de.; SOUZA, P. E. GUIMARÃES, L. G. de; ANDRADE, M. A. Avaliação do potencial fungitóxico do óleo essencial de Syzgium aromaticum (L.) Merr \& Perry (cravo-da-índia). Tecnológica, Santa Cruz do Sul, v. 11, n. 1, p. 11-14, 2007.

SCHMUTZ, J.; MCCLEAN, P. E.; MAMIDI, S.; WU, G A.; CANNON, S. B; GRIMWOOD, J. A reference genome for common bean and genomewide analusis os dual domestications. Nature Genetics. Nature Publishing Group. Jun.2014. Disponível em:< https://www.ncbi.nlm.nih.gov/pubmed/24908249>. Acessado em 03 Jan. 2017.

SHARMA, N; TRIPATHI, A. Efeitos do óleo essencial do epicarpo de Citrus sinensis (L.) Osbeck sobre crescimento e morfogênese de Aspergillus niger (L.) Van Tieghem. p124. Microbiol Revista, p.337-44, 2008.

SHIRAISHI, S. Allelopathic activity of leaching from dry leaves and exudate from roots of ground cover plants assayed on agar. Weed Biology and Management, v.2, n.3, p.133-42, 2002.

SILVA, F. S.; PORTO, A. G.; PASCUALI, L. C.; SILVA, F. T. C. Viabilidade do armazenamento de sementes em diferentes embalagens para pequenas propriedades rurais. Revista de Ciências AgroAmbientais, v. 8, p.45-56, 2010.

SILVA, M.; SOUZA, H. R. T.; DAVID, H. M. S. S.; SANTOS, L. M.; SILVA, R. F.; AMARO, H. T. R. Qualidade fisiológica e armazenamento de sementes de feijão-comum produzidas no norte de Minas Gerais. Revista Agro Ambiente, v.8, p.97-103, 2014.

SIMÕES, C. M. O.; SPITZER, V. Óleos essenciais. Farmacognosia: da planta ao medicamento. Florianópolis: Editora UFSC, cap. 8, p.397-425, 1999.

SOUZA, A. E. F.; ARAUJO, E.; NASCIMENTO, L. C. Atividade antifúngica de extratos de alho e capim-santo sobre 
o desenvolvimento de Fusarium proliferatum isolado de grãos de milho. Fitopatololgia Brasileira, Brasília , v. 32, n. 6, p. 465-471, 2007.

SOUZA, S. A. M; STEIN, V. C.; CATTELAN, L. V.; BOBROWSDI, V. L.; ROCHA, B. H. G. Utilização de sementes de alface e de rúcula como ensaios biológicos para avaliação do efeito citotóxico e alelopático de extratos aquosos de plantas medicinais. Revista de Biologia e Ciência da Terra, João Pessoa, v.5, n.1, 2005.

STÜLP, J. L.; BATTISTUS, A. G.; ISTCHUK, A. N.; MÜlLER, M. A.; MIORANZA, T. M.; KUHN, O. J. Ação de Óleo Essencial de Laranja em diferentes concentrações e do fungicida químico Carboxim + Thiram sobre a germinação e incidência de doenças em sementes de trigo (Triticum aestivum). Cadernos de Agroecologia, v. 6, n. 2, p. 385-389, 2011.

TEIXEIRA, C. A. Potencialidade do tratamento de sementes com óleos essenciais no patossistema Stenocarpella maydis milho. Dissertação (mestrado) - Universidade Federal de Lavras, UFLA - Lavras, p.39, 2010.

TRAJANO, V. N; LIMA, E. O; SOUZA, E. L; TRAVASSOS, A. E. R. Propriedade antibacteriana de óleos essenciais de especiarias sobre bactérias contaminantes de alimentos. Ciência e Tecnologia de Alimentos. Campinas, v. 29, n. 3, p. 542-545, 2009.

VIEGAS, E. C.; SOARES, A.; CARMO, M. G. F.; ROSSETTO, C. A. V. Toxicidade de óleos essenciais de alho e casca de canela contra fungos do grupo Aspergillus flavus. Horticultura Brasileira, Brasília, v.23, n.4, p.915-919, 2005. 